\section{Consideraciones en el manejo del aneurisma aórtico micótico secundario a aortitis por salmonella}

\section{Considerations in the management of ruptured mycotic aortic aneurysm secondary to salmonella aortitis}

\section{Sr. Editor:}

He leído con interés el artículo "Un caso inusual de rotura de aorta no aneurismática secundaria a aortitis por Salmonella" de Gentille D. (abril de 2016) y quisiera exponer mis observaciones:

1.- El artículo menciona que la aorta se ve calcificada pero además está trombosada, hecho frecuente en pacientes ateromatosos revascularizados por vía extraanatómica como en el caso expuesto, un bypass axilobifemoral. En la imagen radiológica se identifica contraste en el retroperitoneo por extravasación, pero no en la aorta.

Si bien las imágenes son pocas, lo que se ve es una ruptura contenida de la aorta distal o probablemente de vasos ilíacos, pues la imagen de ruptura coincide con la bifurcación aortoilíaca. Hace falta una imagen más precisa del origen de esta lesión de tipo aneurisma micótico, que suele ser pequeña.

2.- Una rotura aórtica debiera asociarse a un gran hematoma retroperitoneal, hecho que no se describe en el caso expuesto, pero sí podría esperarse en el caso de un aneurisma micótico complicado ${ }^{2}$.

3.- En el caso del paciente intervenido, se drenó y se tomaron cultivos, pero llama la atención que no se describa si se ligó la aorta infrarrenal ni si se hizo o no la resección del segmento infectado, que la misma autora describe como el tratamiento clásico standard, sobre todo en el caso de un bypass axilobifemoral al cual el paciente ya había sido sometido previamente. Así se logra controlar la infección; el riesgo de estallido del muñón aórtico que se puede ver en estos casos es reducido por la trombosis aórtica previa.

4.- Si bien la terapia endovascular es hoy en día un tratamiento muy atractivo porque resuelve la urgencia y se asocia a menor mortalidad ${ }^{3}$, en el caso expuesto no parece aplicable por la dificultad de acceso asociada a la trombosis ateromatosa aórtica.

5.- Por último, son poco claros los términos "gas intravascular" como hallazgo del TAC ni de "packing endovascular con surgicel" como técnica quirúrgica.

Dr. Alejo Chávez A.

Cirujano Vascular Hospital Naval de Viña del Mar Facultad de Medicina, Universidad de Valparaíso, Chile.

Se otorgó posibilidad de réplica a los autores aludidos. No enviaron respuesta.

\section{Referencias}

1. Gentille D. Un caso inusual de rotura de aorta no aneurismática secundaria a aortitis por Salmonella. Rev Med Chile 2016; 144: 534-43.

2. Hwa Lee M, Chan P, Jeng Chiou H, Keung Cheung W. Diagnostic imaging of Salmonella-related mycotic aneurysm of aorta by CT. Clin Imag 1996; 20: 26-30.

3. Sörelius K, Mani K, Björck M, Sedivy P, Wahlgren CM, Taylor P, et al. Endovascular treatment of mycotic aortic aneurysms: a European multicenter study. Circulation 2014; 130: $2136-42$.
La importancia de reportar la validez y confiabilidad en los instrumentos de medición: Comentarios a Arancibia et al

\section{The importance of reporting validity and reliability in} measuring instruments: Comments to Arancibia et al

\section{Sr. Editor:}

Recientemente se publicó un artículo acerca del funcionamiento psicosocial en pacientes agudos y crónicos no psiquiátricos en régimen hospitalario, la misma que es una contribución importante al campo de la salud mental ${ }^{1}$. En dicho estudio se utilizan instrumentos autoinformados para extraer conclusiones.
No obstante, los autores no proporcionan información suficiente respecto a los instrumentos utilizados, no reportando las propiedades psicométricas de los test, como la validez y confiabilidad.

La validez puede ser entendida como "el grado en que la evidencia y la teoría apoyan la interpretación"2. En la actualidad se conocen cinco fuentes de validez: basada en el contenido, en la estructura interna, en relación con otras variables, en las consecuencias del instrumento y en los procesos de respuesta ${ }^{3}$. El reportar la fuente de validez al que fue sometido el instrumento autoinformado permite garantizar la interpretabilidad de las conclusiones extraídas en base al estudio; o en su defecto, reconocer las limitaciones del mismo. 
En el medio científico, la fuente de validez más utilizada es la basada en la estructura interna, la misma que utiliza la técnica estadística denominada análisis factorial ${ }^{4}$. Esta fuente de evidencia permite establecer la cantidad de factores que subyacen a los ítems y el peso de cada uno en el test ${ }^{4}$. Otra fuente de validez muy utilizada es la basada en el contenido que toma como referente el criterio de jueces expertos en la valoración de los ítems con respecto al constructo ${ }^{5}$.

Por otro lado, la confiabilidad puede ser entendida como una propiedad de las puntuaciones del test y en su versión más clásica denota la proporción de varianza verdadera ${ }^{6} \mathrm{y}$ está vinculada al error de medición. Por ende, a mayor confiabilidad, menor error de medida.

En los últimos años los métodos de consistencia interna han tomado relevancia elaborándose así diferentes coeficientes como: El alfa de Cronbach, Omega, Theta de Armor y Coeficiente H. La elección del coeficiente de confiabilidad está sujeta a las características de los datos a analizarse. Sin embargo, es frecuente utilizar el alfa de Cronbach, que seguramente los test reportados en el artículo ostentan este estimador de confiabilidad.

En ese sentido, la confiabilidad y validez son propiedades importantes de ser reportadas porque permite al lectorconocer el nivel de precisión y evidencia de los instrumentos utilizados, que derivarán en conclusiones coherentes en el estudio.

José Luis Ventura-León Universidad Privada del Norte, Lima, Perú.

\section{Referencia}

1. Arancibia M, Behar R, Marín S, Inzunza N, Madrid E. Funcionamiento psicosocial en pacientes agudos y crónicos no psiquiátricos en régimen hospitalario: depresión, alexitimia y falta de asertividad. Rev Med Chile 2016; 144 (11): 142431.

2. American Educational Research Association, American Psychological Association, \& National Council on Measurement in Education. Standards for educational and psychological testing. Washington, DC: American Educational Research Association; 2014.

3. Sireci S, Padilla J. Validating assessments: introduction to the special section.Psicothema 2014; 26: 97-9.

4. Rios J, Wells C. Validity evidence based on internal structure. Psicothema 2014; 26: 108-16.

5. Sireci S, Faulkner-Bond M. Validity evidence based on test content. Psicothema 2014; 26: 100-7.

6. Muñiz J.Teoría clásica de los test. Madrid: Ediciones Pirámide; 1996.

Financiación: Ninguna

Conflicto de intereses: Ninguno

Correspondencia a:

José Luis Ventura-León

jventuraleon@gmail.com

Av. Tingo María 1122, Breña, Lima 